\title{
Magnetometry as a Tool to Estimate the Pollution of Marine Environment Around Small Shipwrecks (Gulf of Gdańsk) - Preliminary Results
}

\author{
Magdalena GWIZDAŁA ${ }^{1}$, Maria JELEŃSKA ${ }^{1}$, \\ and Leszek ŁĘCZYŃSKI ${ }^{2}$
}

\author{
${ }^{1}$ Institute of Geophysics, Polish Academy of Sciences, Warszawa, Poland \\ e-mail: mgwizdala@igf.edu.pl \\ ${ }^{2}$ University of Gdańsk, Institute of Oceanography, Gdynia, Poland
}

\begin{abstract}
Magnetic properties of deposits around the shipwrecks ("Munin" and "Abille") in the Gulf of Gdańsk were investigated. Values of magnetic susceptibility $(\chi)$ are relatively low; however, they reveal significant differences between investigated sites. The values of $\chi$ around "Abille" wreck were $5-8 \times 10^{-8} \mathrm{~m}^{3} / \mathrm{kg}$. Around "Munin" wreck results were more diversified reaching value of $\chi$ between $3.07 \times 10^{-8} \mathrm{~m}^{3} / \mathrm{kg}$ and $12.92 \times 10^{-8}$ $\mathrm{m}^{3} / \mathrm{kg}$. The spatial variability of $\chi$ coincided with near-bottom water currents distribution in the Gulf of Gdańsk. Magnetic minerals were identified by thermomagnetic analysis. Around "Abille" wreck we have found magnetite with small amount of maghemite or hematite. The "Munin" sediments include only one magnetic phase; in several samples it is magnetite, in the others - maghemite. Day-Dunlop plot shows that "Abille" set is shifted towards lower magnetization ratio and higher coercivity ratio. The correlation between the distribution of $\chi$ and hydrodynamic condition around shipwrecks allows to determine the direction of contaminant transport.
\end{abstract}

Key words: environmental magnetism, magnetic susceptibility, sediment pollution, shipwrecks. 


\section{INTRODUCTION}

In the bottom of Gulf of Gdańsk there are a lot of sunk ships. Many of them still have significant amounts of fuel, ammunition or chemical weapons in their holds (Rogowska et al. 2010). The steel bodies of wrecks are damaged by salty water, which results in the increasing corrosion rate due to such factors as $\mathrm{pH}$, oxygen content, temperature, pressure and the action of water currents. Destruction of the fuel and ammunition tanks is a source of contamination (Rogowska et al. 2015).

Sediment samples may constitute an important source of information about the extent of contamination and its impact on surrounding ecosystems (Rogowska et al. 2015). Especially, the role of sediments is the storage and being carriers of pollutants in aquatic systems, and is the final fate of toxins as a result of sorption process, diffusion, chemical reactions and biological activities (Corazza et al. 2012). To specify the amount of pollution and its impact on the marine environment, a wide range of analyses should be performed.

Hitherto, a lot of various research was made in the vicinity of wrecks, mainly using analytical procedures such as: ecotoxicological studies, chemical analysis, biological and chemometric studies. Analytical techniques allow to determine pollutant concentrations in sediment samples, but they are not reliable impact indicators of the complex chemical mixtures on ecosystems (Kudłak et al. 2012). In the light of this, it makes sense to supplement such information with the results of magnetic methods.

Magnetometry is an inexpensive and fast tool for qualitative estimation of the environmental contamination degree in soils, sediments or water. The application of this method is based on the fact that the magnetic properties of iron oxides and sulphides present in the pollutions are connected with heavy metals and toxic elements which might be hazardous to the environment (Jordanova et al. 2012). In the last 20 years, many studies have been focused on the use of the magnetic method to study environment contamination (e.g., Jeleńska et al. 2008, Magiera et al. 2006, Muxworthy et al. 2003, Bućko et al. 2011, Górka-Kostrubiec et al. 2014).

In 1999, the Maritime Institute in Gdańsk has started a preliminary study on the nature and extent of the contamination in the Gulf of Gdańsk. In this area, environment around s/s "Stuttgart" wreck was precisely studied during past few years (Kudłak et al. 2012, Rogowska et al. 2010, 2015). This showed that a seabed environment had been polluted in the area of 2.3 ha around this wreck (Maritime Institute in Gdańsk 1999). Smaller wrecks occurring in the Gulf of Gdańsk, such as "Trałowiec” or „Abille”, have not been evaluated in this regard. Therefore, the aim of this work is to investigate by use of the magnetometry whether the existence of relatively small wrecks affects marine pollution. 


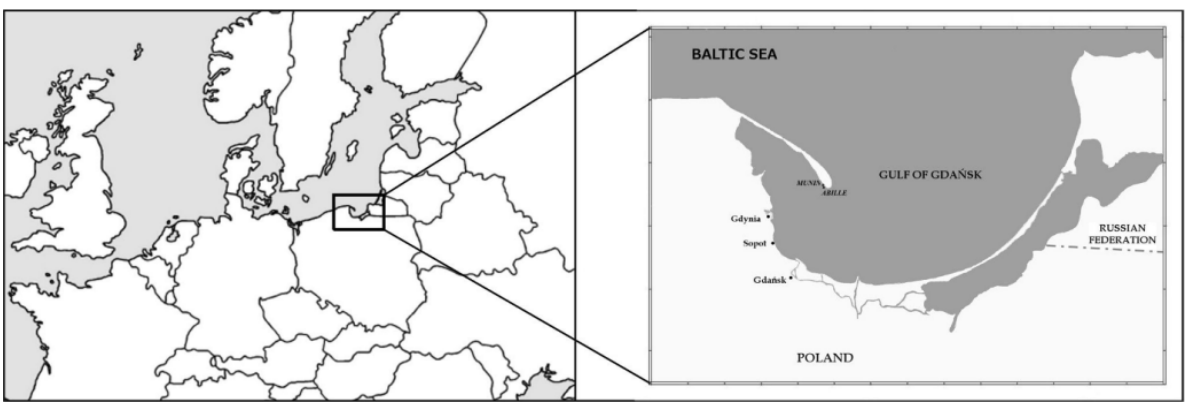

Fig. 1. Location of “Munin” and „Abille” wrecks in the Gulf of Gdańsk.

Wreck of "Munin", called also "Trałowiec", was the warship used by German Navy ("Reischmarine" and "Kreigsmarine"), rebuilt from a fishing trawler and launched in 1916. In 1945, the warship had sunk after a collision, close to the port of Hel (Fig. 1) (http://www.balticwrecks.com/pl/ wraki/).

The tugboat "Abille" was built in 1936 in Leith, France. In 1940 it was incarnated to "Kreigsmarine" in Benodet. The ship probably has sunk in winter 1945 while helping another vessel which had problems at Hel's roadstead (http://www.balticwrecks.com/pl/wraki/).

\section{MATERIALS AND METHODS}

\subsection{Study sites and sample handling}

The sediment samples were collected around "Munin” and „Abille” wrecks at a distance of 100 and $200 \mathrm{~m}$ (Fig. 2). 16 surface samples (M1-M8, A1A8), about $500 \mathrm{~g}$ in weight, were taken using the "Van Veen's" grab holder during cruises on $\mathrm{k} / \mathrm{h}$ "Oceanograf 2". Samples were transported to the laboratory and stored at $-20^{\circ} \mathrm{C}$. Before magnetic measurements, sediment samples were dried to constant weight.

\subsection{Magnetic methods}

The magnetic susceptibility per unit mass $(\chi)$ was measured using the MultiFunction Kappabridge MFK1-FA (AGICO, Czech Republic). The measurements of $\chi$ were made at two different frequencies: 976 and $15600 \mathrm{~Hz}$ of magnetic field $(200 \mathrm{~A} / \mathrm{m})$ to determine $\chi_{\mathrm{fd} \%}$ parameter according to the definition of Thompson and Oldfield (1986):

$$
\frac{\chi_{\mathrm{LF}}-\chi_{\mathrm{HF}}}{\chi_{\mathrm{LF}}} 100 \%
$$




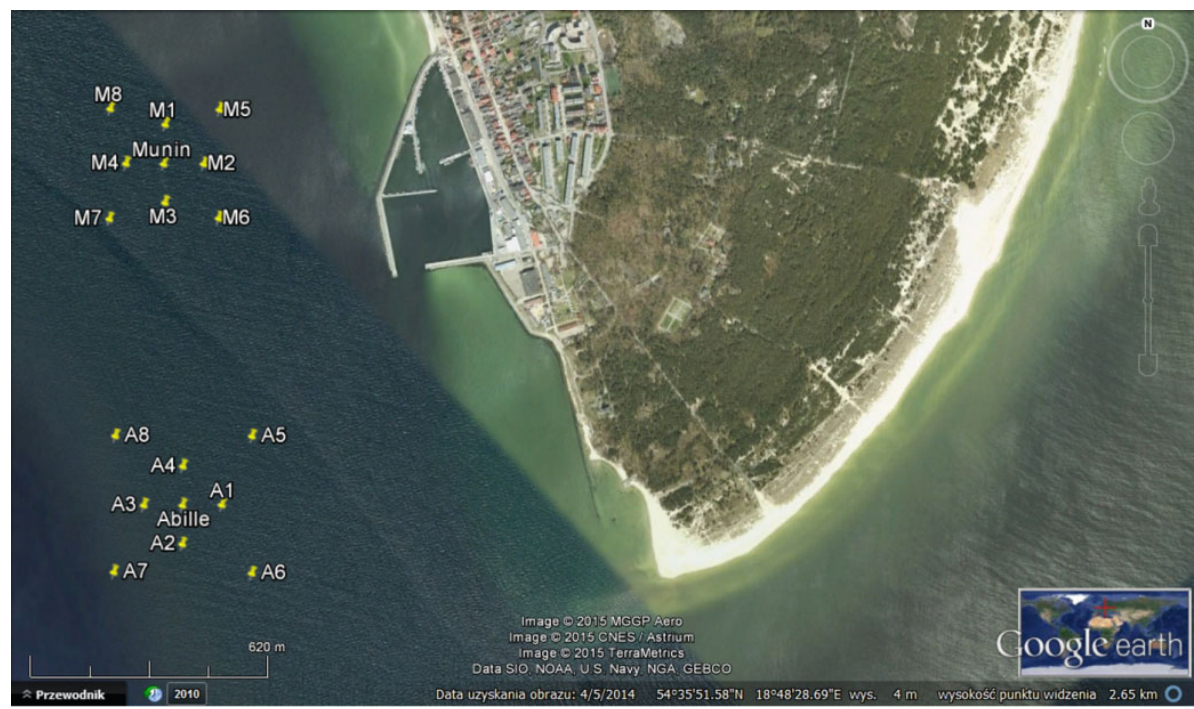

Fig. 2. Positions of sediment sampling sites around "Munin" and "Abille" wrecks.

where $\chi_{\mathrm{LF}}$ is the susceptibility at the low frequency, whereas $\chi_{\mathrm{HF}}-$ at the high frequency.

Hysteresis loop parameters $(B c-$ coercivity, $B c r-$ coercivity of remanence, $M r s$ - saturation remanence, $M s$ - saturation magnetization) were determined by the vibrating magnetometer VSM (Molspin, Great Britain), working on maximum magnetic field of $1 \mathrm{~T}$. These parameters served for the construction of the Day-Dunlop plot (Day et al. 1977, Dunlop $2002 a, b)$, which defines the domain state of magnetic particles.

Identification of magnetic minerals consists of thermomagnetic analyses such as saturation isothermal remanent magnetization SIRM(T) or volume magnetic susceptibility $\kappa(T)$ dependence on temperature. Thermomagnetic curves of SIRM $(T)$ were set by use the device made by the Tus Electronics (Poland). The magnetic fraction (FM) was separated from each sample by means of neodymium magnet, for the better identification of magnetic minerals. First, each sample was magnetized in a field of $9 \mathrm{~T}$ using the MMPM10 pulse magnetiser. Afterwards, the sample was heated up to $700^{\circ} \mathrm{C}$ in nonmagnetic space. The changes of $\kappa(\mathrm{T})$ were measured by means of a kappabridge KLY-3 with high-temperature extensions CS-3 (AGICO, Czech Republic). The measurements were performed during heating in temperature ranges from room temperature to $700^{\circ} \mathrm{C}$ and cooling to room temperature. 


\section{RESULTS}

The values of mass magnetic susceptibility of samples around wrecks are relatively small. The highest value does not exceed $\chi<13 \times 10^{-8} \mathrm{~m}^{3} / \mathrm{kg}$, whereas the smallest amounts to $3.07 \times 10^{-8} \mathrm{~m}^{3} / \mathrm{kg}$. It is the range of magnetic susceptibility values for samples from "Munin". Values of $\chi$ for samples from the area of "Abille" wreck are not so varied $\left(5<\chi<8 \times 10^{-8}\right.$ $\mathrm{m}^{3} / \mathrm{kg}$ ). Figure 3 shows the spatial distribution of $\chi$. The values of magnetic susceptibility increase towards SWW, in the vicinity of "Munin" wreck and towards SW around "Abille" wreck.

The frequency dependence in the range of SP/SD boundary of magnetic susceptibility $\left(\chi_{\mathrm{fd}} \%\right)$ was measured to detect the content of superparamagnetic grains in a sample. For all samples, this parameter does not exceed $3 \%$. This indicates that sediment samples in the vicinity of wrecks contain low concentration of SP grains.

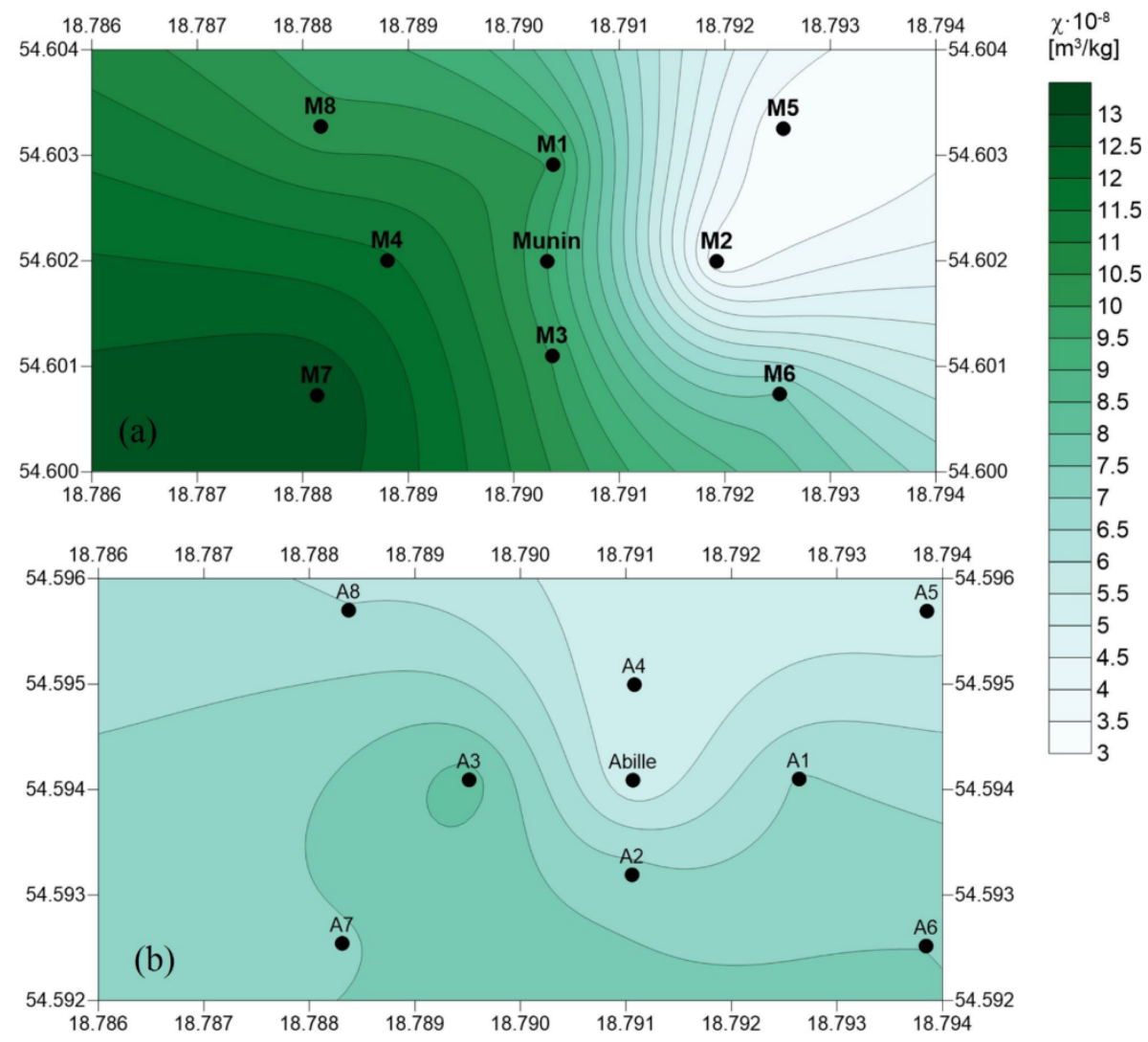

Fig. 3. Spatial distribution of mass magnetic susceptibility in the vicinity of: (a) "Munin" and (b) "Abille" wrecks. 

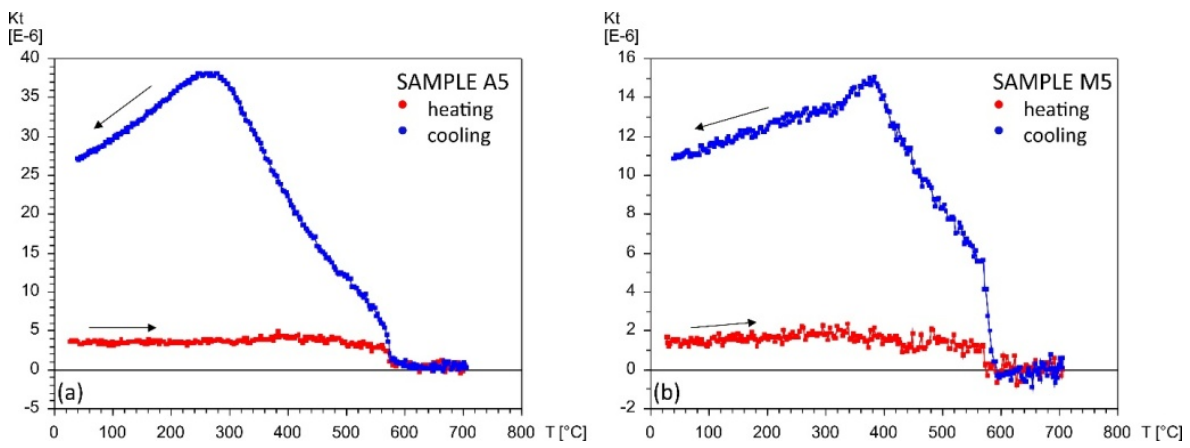

Fig. 4. Temperature dependence of volume magnetic susceptibility for selected samples from: (a) "Abille" and (b) "Munin" wrecks.

Heating curves of the temperature dependence of susceptibility for the samples from "Abille" set are relatively constant until reaching a value about $580^{\circ} \mathrm{C}$ when $\kappa$ decreases to zero (Fig. $4 \mathrm{a}$ ), which suggests the occurrence of magnetite (Dunlop and Özdemir 1997). During cooling, the single characteristic Curie point occurs equal to that at heating curve and wide peak of $\kappa$ near $280^{\circ} \mathrm{C}$, which is probably the size effect. In the "Munin" set, curves of
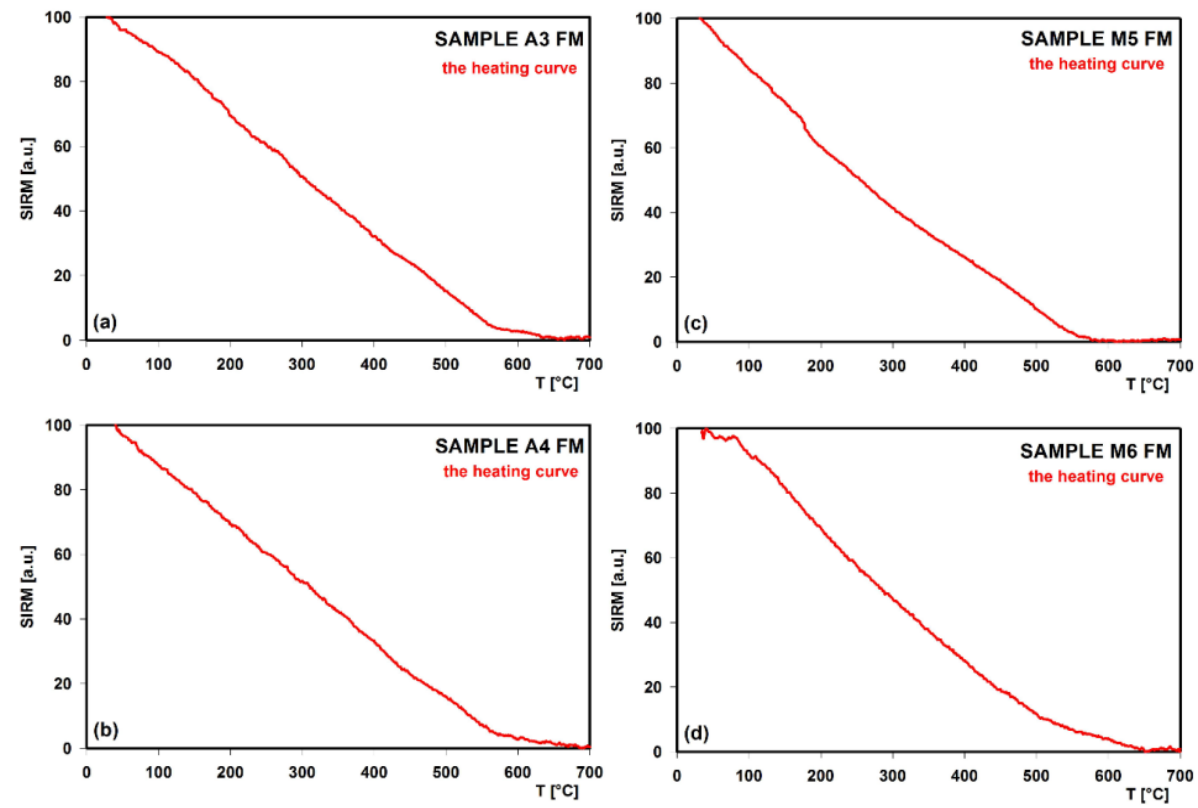

Fig. 5. Thermal demagnetization of saturation isothermal remanence magnetization (SIRM) for selected sediment sample from: (a, b) "Abille" and (c, d) "Munin" wrecks. 


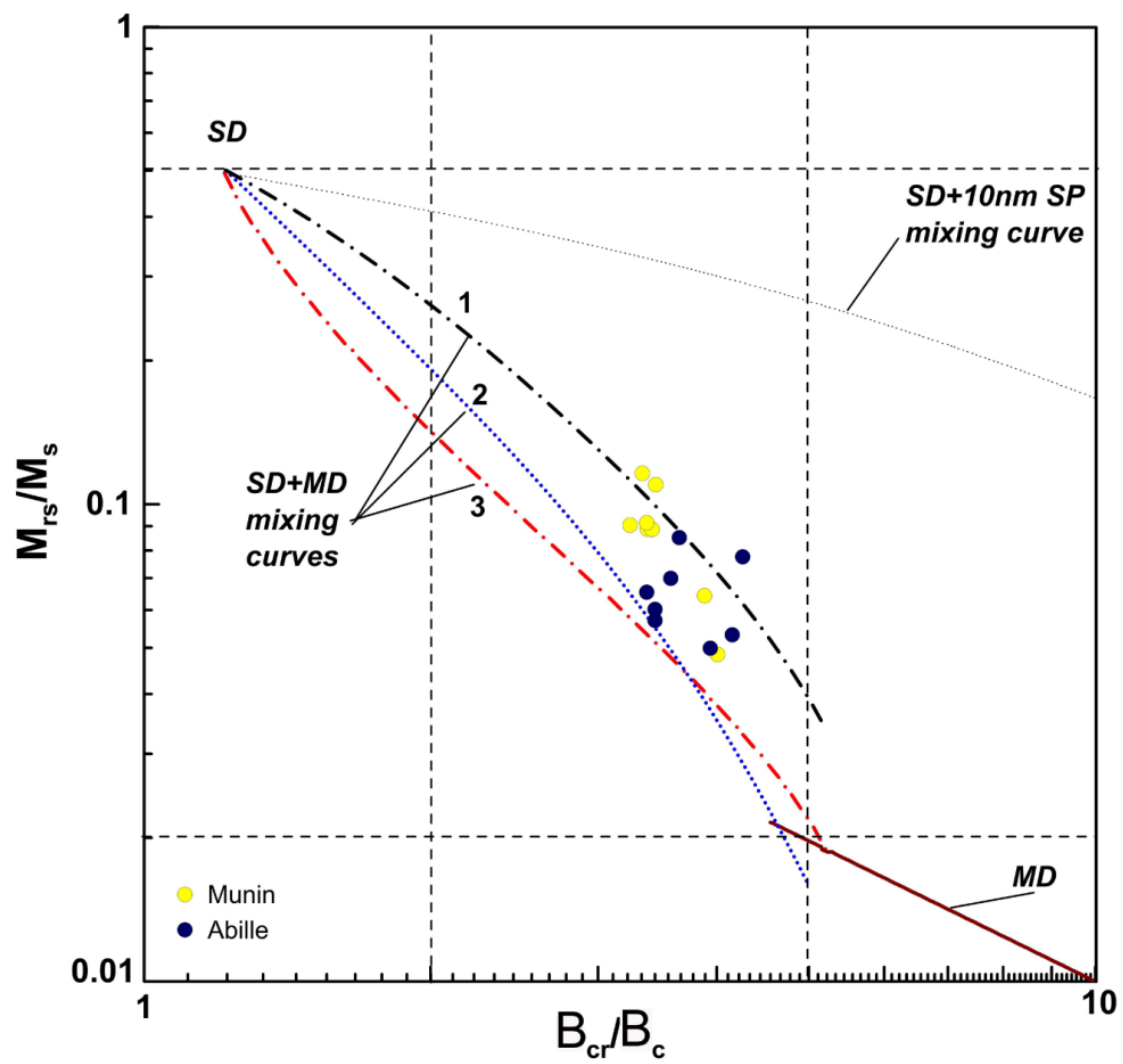

Fig. 6. Hysteresis ratios Mrs/Ms versus $\mathrm{Bcr} / \mathrm{Bc}$ shown on Day-Dunlop plot (Day et al. 1977, Dunlop 2002a, b). Dotted line represents theoretically calculated mixing curve of SD + $10 \mathrm{~nm}$ SP grains. Dashed curves $(1,2,3)$ represent different mixing curves of $\mathrm{SD}+\mathrm{MD}$.

$\kappa(T)$ are similar to those for "Abille" samples (Fig. 4b). Curves of $\kappa(T)$ register those chemical alteration caused by heating. For this reason, Curie temperature observed is related to magnetic minerals which can be different from contained in fresh samples, because of alteration occurring at an elevated temperature.

Curves of continuous thermal demagnetization of SIRM give us information about unblocking temperature $\left(T_{\mathrm{ub}}\right)$ which is close to the Curie temperature for minerals in fresh samples. In "Abille" set, we observed, besides the main carrier - magnetite, also tails with $T_{\mathrm{ub}}$ between 650 and $680^{\circ} \mathrm{C}$ characteristic for maghemite (Fig. 5a) and hematite (Fig. 5b). According to Jeleńska et al. (2010) these minerals are often reduced to magnetite during heating in the Czech kappabridge device. The "Munin" set can be divided in- 
to two groups in terms of composition of magnetic minerals. The SIRM(T) plot reveals the dominance of magnetite with Tub in the range of $565-590^{\circ} \mathrm{C}$ in the first group (Fig. 5c), which includes most of the samples. In the second group, the total thermal demagnetization occurs at around $630-660^{\circ} \mathrm{C}$ (Fig. 5d) which corresponds to Tub of maghemite. We do not observe this maghemite on $\kappa(T)$ curves, because it is probably reduced during heating.

On the Day-Dunlop plot most of the samples are located between the first and third SD+MD mixing curves (Fig. 6) (Day et al. 1977, Dunlop 2002a, b). The "Munin" set of samples is clustered between $0.08<\mathrm{M}_{\mathrm{rs}} / \mathrm{M}_{\mathrm{s}}<$ 0.13 and $3.1<\mathrm{B}_{\mathrm{cr}} / \mathrm{B}_{\mathrm{c}}<3.5$, except for two samples (M2, M5), which are included in "Abille" series, whereas the "Abille" group of samples is slightly shifted towards lower magnetization ratio and higher coercivity ratio $\left(\mathrm{Mrs} / \mathrm{Ms}<0.09\right.$ and $\left.B_{\mathrm{cr}} / \mathrm{B}_{\mathrm{c}}>3.3\right)$.

\section{DISCUSSION}

The "Abille" group of samples contains magnetite as a main magnetic phase and contribution of second phase identified as maghemite and hematite. The presence of fine grained magnetite is observed at $580^{\circ} \mathrm{C}$ on heating curves of $\kappa(T)$ and by unblocking temperature in the range of $560-570^{\circ} \mathrm{C}$ observed on the SIRM curves. The second phase is observed only on SIRM(T) curves as a tail with $T_{\mathrm{ub}}$ between 650 and $680^{\circ} \mathrm{C}$. In the "Munin" group of samples, usually one magnetic phase is observed, which is magnetite or maghemite with $T_{\text {ub }}$ in the range of $565-590^{\circ} \mathrm{C}$ and $630-660^{\circ} \mathrm{C}$, respectively.

The results of measurements of hysteresis parameters give us a possibility to deduce the grain size of the magnetic fraction from Day-Dunlop plot. The "Abille" group of samples is mainly a mixture of SD and MD particles. The samples from "Munin" set are located above the "Abille" set which indicates the presence of smaller size of grains. The SD + MD mixing curves describe the shape of grains. Most samples from "Munin" group occur around the first $\mathrm{SD}+\mathrm{MD}$ mixing curve which indicates the predominant presence of elongated grains. The hematite traces can influence the position of "Abille" samples on Day-Dunlop plot. The closer cluster of "Munin" than "Abille" samples can be caused by the presence of two magnetic phases in "Abille" sediments.

The $\chi$ values for the "Abille" set are less than those for the "Munin" set. In "Abille" samples, besides magnetite as the main carrier, some amounts of maghemite and hematite occur. As hematite is about two orders of magnitude weaker than magnetite (Evans and Heller 2003), it can influence the total magnetic signal. Various magnetic properties of "Abille" and "Munin" deposits demonstrate that both shipwrecks are sources of different magnetic pollutants. The reason is different oxidation conditions around the ship- 


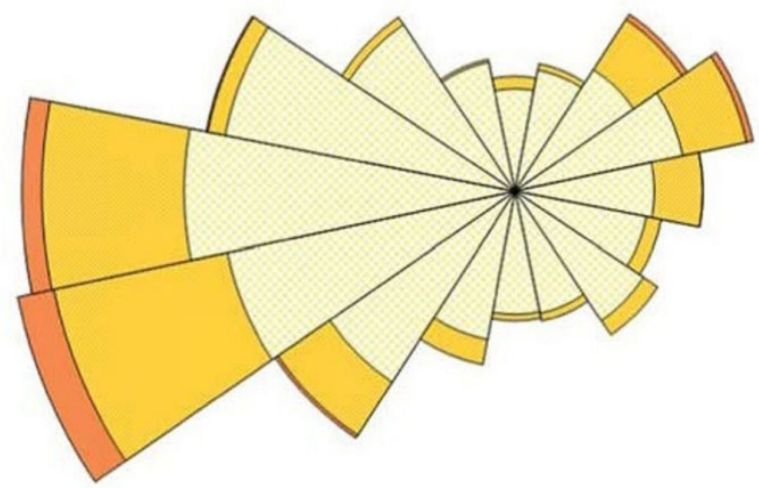

[cm/s]

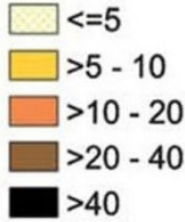

Fig. 7. Water currents distribution in the near-bottom layer $(18-24 \mathrm{~m})$ in the western part of the Gulf of Gdańsk (data for 2009 based on the HIROMB model).

wrecks. Although $\chi$ values are not significantly enhanced, they point to SWW distribution.

The factor having an impact on the distribution of $\chi$ is the location of shipwrecks, close to the port of Hel (Fig. 1). Wreck of "Munin" is located more inside the bay and closer to the port (Fig. 2) than the "Abille" one, which is more outside. Around Hel, the dominant winds are from the west (Łęczyński 2009). Current direction and intensity are strongly associated with wind speed, direction and duration (Kowalik 1990). Therefore, the flow pattern for the Gulf of Gdańsk is irregular and heterogeneous, making it difficult to measure and interpret (Robakiewicz 2009). In shallow coastal zones, currents flow parallel to the shore with speeds usually less than $50 \mathrm{~cm} / \mathrm{s}$ (Kowalik 1990). Local currents have a significant impact on measurements of water movements in the Baltic Sea (Lomniewski et al. 1975), whereas the dynamics of the near-bottom water masses has the most important influence on the seabed conditions in the vicinity of wrecks (Kudłak et al. 2012).

Figure 7 shows the water currents distribution in the near-bottom layer (18-24 m) in the western part of the Gulf of Gdańsk. Currents flow is mainly from the west and south-west, which coincides with the direction of magnetic susceptibility distribution around both wrecks, especially the "Munin" one (Fig. 3).

The relatively low $\chi$ values can be caused by the fact that the samples were collected at the surface of seabed. Sand, which is a basic element of surface sediments, is easily permeable and the magnetic susceptibility can be higher in deeper layers. Another aspect is sedimentation - the fresh sand masses may cover the older layers and hide a real contamination. 


\section{CONCLUSIONS}

The results of the study show that the main carrier of magnetic information in the sediment samples collected around shipwrecks is magnetite with small amount of maghemite and hematite in "Abille" set and one mineral - magnetite or maghemite in "Munin" set. Low concentration of strong magnetic minerals results in low $\chi$ values. In spite of low $\chi$ value, which indicates that the contamination in the vicinity of "Munin" and "Abille" wrecks is not especially large, it is possible to trace the distribution of magnetic susceptibility correlated with the distribution of currents or wind direction. That in turn allows to determine the direction of contaminant transport.

These results are a preliminary recognition of applicability of magnetic method to estimate the pollution of marine environment around small shipwrecks. In the future, it would be worth to investigate the sediment cores in the vicinity of "Munin" and "Abille" wrecks, which would give the possibility of $3 \mathrm{D}$ visualisation of contaminants arising during shipwrecks corrosion. The results of magnetic study should also be compared with mineral composition, concentration of heavy metals and petroleum substances, which will be an additional justification for the application of this method to environmental assessments.

\section{References}

Bućko, M.S., T. Magiera, B. Johanson, E. Petrovský, and L.J. Personen (2011), Identification of magnetic particulates in road dust accumulated on roadside snow using magnetic, geochemical and micromorphological analyses, Environ. Pollut. 159, 5, 1266-1276, DOI: 10.1016/j.envpol.2011.01.030.

Corazza, M.Z., T. Abra, F. Grandis Lepri, S.M.N. Gimenez, E. Oliveira, and M.J. Santos (2012), Monte Carlo method applied to modelling copper transport in river sediments, Stoch. Environ. Res. Risk Assess. 26, 8, 10631079, DOI: 10.1007/s00477-012-0564-2.

Day, R., M. Fuller, and V.A. Schmidt (1977), Hysteresis properties of titanomagnetites: Grain-size and compositional dependence, Phys. Earth Planet. Inter. 13, 4, 260-267, DOI: 10.1016/0031-9201(77)90108-X.

Dunlop, D.J. (2002a), Theory and application of the Day plot (Mrs/Ms versus $\mathrm{Hcr} / \mathrm{Hc})$ : 1. Theoretical curves and tests using titanomagnetite data, J. Geophys. Res. 107, B3, 2056, DOI: 10.1029/2001JB000486.

Dunlop, D.J. (2002b), Theory and application of the Day plot (Mrs/Ms versus $\left.\mathrm{H}_{\mathrm{cr}} / \mathrm{H}_{\mathrm{c}}\right)$ : 2. Application to data for rocks, sediments, and soils, J. Geophys. Res. 107, B3, 2057, DOI: 10.1029/2001JB000487. 
Dunlop, D.J., and Ö. Özdemir (1997), Rock Magnetism: Fundamentals and Frontiers, Cambridge University Press, Cambridge, 573 pp.

Evans, M., and F. Heller (2003), Environmental Magnetism: Principles and Applications of Enviromagnetics, Academic Press.

Górka-Kostrubiec, B., M. Jeleńska, and E. Król (2014), Magnetic signature of indoor air pollution: household dust study, Acta Geophys. 62, 6, 1478-1503, DOI: 10.2478/s11600-014-0238-1.

Jeleńska, M., A. Haaso-Agopsowicz, M. Kądziałko-Hofmokl, B. Kopcewicz, A. Sukhorada, K. Bondar, and Z. Matviishina (2008), Magnetic structure of polluted soil profiles from Eastern Ukraine, Acta Geophys. 56, 4, 10431064, DOI: 10.2478/s11600-008-0036-8.

Jeleńska, M., A. Haaso-Agopsowicz, and B. Kopcewicz (2010), Thermally induced transformation of magnetic minerals in soil based on rock magnetic study and Mössbauer analysis, Phys. Earth Planet. Int. 179, 3-4, 164-177, DOI: 10.1016/j.pepi.2009.11.004.

Jordanova, D., N. Jordanova, Ph. Lanos, P. Petrov, and T. Tsacheva (2012), Magnetism of outdoor and indoor settled dust and its utilization as a tool for revealing the effect of elevated particulate air pollution on cardiovascular mortality, Geochem. Geophys. Geosyst. 13, 8, Q08Z49, DOI: 10.1029/2012GC004160.

Kowalik, Z. (1990), Prądy. In: E. Majewski (ed.), Zatoka Gdańska, Wydawnictwo Geologiczne, Warszawa (in Polish).

Kudłak, B., J. Rogowska, L. Wolska, M. Kałas, L. Łęczyński, and J. Namieśnik (2012), Toxicity assessment of sediments associated with the wreck of s/s Stuttgart in the Gulf of Gdańsk (Poland), J. Environ. Monit. 14, 1231-1236, DOI: $10.1039 / \mathrm{c} 2 \mathrm{em} 10476 \mathrm{~h}$.

Łęczyński, L. (2009), Morfolitodynamika Przybrzeża Półwyspu Helskiego, Wydawnictwo Uniwersytetu Gdańskiego, Gdańsk (in Polish).

Łomniewski, K., W. Mańkowski ,and J. Zalewski (1975), Morze Battyckie, PWN, Warszawa (in Polish).

Magiera, T., Z. Strzyszcz, A. Kapička, and E. Petrovsky (2006), Discrimination of lithogenic and anthropogenic influences on topsail magnetic susceptibility in Central Europe, Geoderma 130, 3-4, 299-311, DOI: 10.1016/j.geoderma. 2005.02.002.

Maritime Institute in Gdańsk (1999), Ocena zagrożeń środowiska w rejonie wraku Stuttgart (raport wstępny), IMG No.5542, Gdańsk (in Polish).

Muxworthy, A.R., J. Matzka, A.F. Davila, and N. Petersen (2003), Magnetic signature of daily sampled urban atmospheric particles, Atmos. Environ. 37, 29, 4163-4169, DOI: 10.1016/S1352-2310(03)00500-4.

Robakiewicz, M. (2009), Hydrodynamics in the Gulf of Gdańsk (part II), MACHU Fin. Rep. 3, 75-79. 
Rogowska, J., L. Wolska, and J. Namieśnik (2010), Impacts of pollution derived from ship wrecks on the marine environment on the basis of s/s Stuttgart (Polish coast, Europe), Sci. Total Environ. 408, 23, 5775-5783, DOI: 10.1016/j.scitotenv.2010.07.031.

Rogowska, J., B. Kudłak, S. Tsakovski, A. Gałuszka, G. Bajger-Nowak, V. Simeonov, P. Konieczka, L. Wolska, and J. Namieśnik (2015), Surface sediments pollution due to shipwreck s/s "Stuttgart”: a multidisciplinary approach, Stoch. Environ. Res. Risk Assess. 29, 7, 1797-1807, DOI: 10.1007/s00477-015-1054-0.

Thompson, R., and F. Oldfield (1986), Environmental Magnetism, Allen and Unwin, London.

Received 14 October 2015

Received in revised form 1 June 2016

Accepted 15 June 2016 